\title{
EXOPOLYSACCHARIDE SYNTHESIS PRODUCTIVITY \\ BY BACILLUS MUCILAGINOSUS DEPENDING ON THE NITROGEN SOURCE AND ORIGIN OF INOCULUM
}

\section{M. Malinovska}

The extracellular polysaccharide Bacillus mucilaginosus has broad prospects for the use in practice: in medicine (immune-stimulating, immunomodulatory, antiviral, antitumor activity) and animal husbandry (food additive in the diet of farm animals, preserving forage), in oil and mining industry, in the production of ceramics and lubricants, substitutes of known technical oils, antiwear additive in brake and cooling solutions [1-3]. But the works, devoted to the study of principles of growth and synthesis of extracellular polysaccharide $B$. mucilaginosus, are controversial [4-7]. Thus, according to V.H. Aleksandrov and V.S. Podhorskyi et al. $[5 ; 6]$, the potential growth of culture on nitrogen-free environments is possible. Most scientists advocate the need for nitrogen administration to the culture medium composition $[4 ; 7]$. The most thorough study was conducted by K. I. Surman [7]. She showed that $B$. mucilaginosus belongs to oligonitrophils and needs small amounts of nitrogen in the ammonium form $\left(0.03 \% \mathrm{NH}_{4} \mathrm{NO}_{3}\right)$ for its development. The contradiction between the researchers is not only on the need of nitrogen administration to the culture medium, but also on its form. Thus, V. H. Aleksandrov and H. A. Zak [6] believe that organic nitrogen inhibits the growth of bacteria. Other researchers argue that peptone $(0.05 \%)$ and yeast water $(2.0 \%)$ stimulate the growth and sporogenesis of $B$. mucilaginosus $[1 ; 2]$.

The divisiveness of obtained data is, possibly, associated with conducting experiments with different strains of $B$. mucilaginosus, or a mixture of options that are different in physiological and biochemical properties. There is a need for research extension in the direction of physiological and biochemical characteristics of individual strains of $B$. mucilaginosus.

Materials and methods. The subject of the research was C-3 strain of $B$. mucilaginosus obtained from the collection of the Institute of
Mineral Resources of the Ministry of Geology of Ukraine, where it was given to in 1963 by V. H. Alexandrov. For the cultivation of bacteria A-27 medium was used, g/l: sucrose $5.0 ; \mathrm{MgSO}_{4} \times 7 \mathrm{H}_{2} \mathrm{O}-0.5 ; \mathrm{Na}_{2} \mathrm{HPO}_{4} \times 2 \mathrm{~N}_{2} \mathrm{O}-$ 2.0; $\mathrm{FeCl}_{3} \times 6 \mathrm{H}_{2} \mathrm{O}-0.05$; potassium aluminium silicate - 1.0; chalk, powdered with $0.1 \mathrm{~g}$ of silicate - 1.0; $\mathrm{pH} 7.2$ [6]. For the cultivation of bacteria mineral medium A of such composition was also used (g/l): glucose -15.4; $\mathrm{MgSO}_{4} \times 7 \mathrm{H}_{2} \mathrm{O}$ - 0,7; $\mathrm{Na}_{2} \mathrm{HPO}_{4} \times 2 \mathrm{~N}_{2} \mathrm{O}$ - 2.0; $\mathrm{KNO}_{3}-1.0 ; \quad \mathrm{FeCl}_{3} \times 6 \mathrm{H}_{2} \mathrm{O}-0,05$. The composition varied depending on environmental conditions and research objective. Different $\mathrm{N}: \mathrm{C}$ ratio in the environment were created by increasing glucose concentrations. For obtaining $B$. mucilaginosus culture, which does not synthesize exopolysaccharide (EPS), it was 3-5 times passaged in liquid medium with $\mathrm{N}: \mathrm{C}$ ratio $=1: 3$.

Growing B. mucilaginosus was conducted in a periodical process which was carried out in $750 \mathrm{ml}$ flasks with $100 \mathrm{ml}$ of medium on a shaker at $240 \mathrm{rev} . / \mathrm{min}$. The culture medium temperature was $30^{\circ} \mathrm{C}$, cultivation time -24 hours. The volume of seed material made up $5 \%$ of the medium volume. To study the impact of seed material origin on polysaccharide synthesis, the concentration of cells and spores in the medium was determined by Goriaiev chamber, while the concentration of spores after seed material addition to the medium was $6.5 \times 10^{7}$ units $/ \mathrm{ml}$, the concentration of vegetative cells $-7.0-7.4 \times 10^{7}$ cells $/ \mathrm{ml}$. Spore-based seed material was pre-heated at the temperature of $80^{\circ} \mathrm{C}$ for $10 \mathrm{~min}$. to kill vegetative cells.

The content of cells that synthesize exopolysaccharide was determined by weighing technique. The cells were precipitated at $40000 \mathrm{~g}$ for $40 \mathrm{~min}$. Weighing cups with biomass were dried to constant weight at the temperature of $105^{\circ} \mathrm{C}$. To take into account the number of cells in the culture 
liquid, the direct count method in Goriaiev chamber and limiting dilutions method followed by bacterial suspension seeding on agar medium were used.

The amount of extracellular polysaccharide was determined by weighing technique following the three-fold ethanol volume precipitation. For this, the culture liquid (18-24 hrs.) was 2-3 times diluted with physiological solution, centrifuged to precipitate the cells at $40000 \mathrm{~g}$ for $40 \mathrm{~min}$. The supernatant was poured off and polysaccharide was precipitated with three volumes of ethanol from it. Precipitated EPS was separated from alcohol by centrifugation at $6000 \mathrm{rpm}$ for 10 min. Ethanol precipitate was dissolved in distilled water and dialyzed against drinking water one day, against distilled - two days. The polysaccharide was lyophilized to get dry.

Thus, it was found that the optimal nitrogen form for C-3 strain of $B$. mucilaginosus is nitrate form of nitrogen, with which the largest amount of biomass is accumulated and the process of sporulation takes place, which is not provided by the ammonium form of nitrogen.

The content of $2.5 \mathrm{~g} / 1$ of potassium nitrate in medium A provides maximum accumulation of both biomass and extracellular polysaccharide $B$. mucilaginosus.

The Intensity of nitrogen use by $B$. mucilaginosus culture depends on the physiological condition seed material cells: if seed material is used in the form of spores, maximum amount of biomass and extracellular polysaccharide is produced.

As the number of $B$. mucilaginosus culture re-seeding increased in a vegetative state the efficiency of nitrogen source use and the ability to synthesize exopolysaccharide significantly decreases: after the second re-seeding - by $20.0 \%$, after the fourth - by $56.5 \%$, after the sixth - by $127.8 \%$. 